\title{
From Reflection to Self-Assessment: Methods of Developing Critical Thinking in Students
}

\author{
Olha I. Dienichieva ${ }^{1}$, Maryna I. Komogorova ${ }^{2}$, Svitlana F. Lukianchuk ${ }^{2}$, Liudmyla I. Teletska ${ }^{3}$, \\ Inna M. Yankovska ${ }^{3}$ \\ ${ }^{1}$ Department of Foreign Languages and Modern Teaching Techniques, Educational and Research \\ Institute of Foreign Philology, Zhytomyr Ivan Franko State University, \\ 40 Velyka Berdychivska Street, 10008, \\ Zhytomyr, Ukraine. \\ ${ }^{2}$ Foreign Languages and Methodology Department, Faculty of Pedagogy and Psychology, National \\ Pedagogical Drahomanov University, \\ 9 Pyrohova Street, 01601, \\ Kyiv, Ukraine. \\ ${ }^{3}$ Department of Pedagogy and Methods of Primary Education, Faculty of Pedagogy and Psychology, \\ National Pedagogical Drahomanov University, \\ 9 Pyrohova Street, 01601, \\ Kyiv, Ukraine.
}

Received: July 30, 2021. Revised: August 23, 2021. Accepted: August 25, 2021. Published: August 27, 2021.

\begin{abstract}
The main task of a higher education institution is to prepare a student for professional duties in a rapidly changing world. To effectively perform this task, it is necessary to give students not only knowledge but also to develop the necessary skills and abilities, in particular to develop critical thinking. The purpose of this work was to develop a methodology for the development of critical thinking of students, as well as to investigate its effectiveness. The study used the method of synthesis, which developed a method of developing critical thinking of students. To diagnose the effectiveness of the proposed method used the test "Critical Thinking" L. Starkey adapted by $O$. Lutsenko. In the study the peculiarities of the development of such critical thinking skills as reflective thinking, self-analysis, awareness of one's own achievements and shortcomings, choice of problem-solving strategy, use of cognitive models of learning (Socratic dialogue, Paul \& Elder taxonomy) are revealed. It was found that the development of critical thinking was achieved through a comprehensive combination of selfassessment and reflection, performing exercises to develop the ability to clearly articulate the problem, find, analyse and interpret relevant information, draw the right conclusions and explanations. The results of this study can be useful to researchers and university professors who are looking for effective methods of developing critical thinking in students.
\end{abstract}

Keywords-Academic performance, cognitive models of learning, critical thinking, metacognitive awareness, reflection, self-analysis, self-assessment, students.

\section{INTRODUCTION}

$\mathrm{O}$ $\mathrm{NE}$ of the most important skills that will ensure the success of professional activities in the 21 st century is critical thinking. The global recession of 2020 caused by the COVID-19 pandemic and related changes in the labor market have led to an increase in the popularity of such skills as critical thinking, analysis and problem solving [1,2]. Critical thinking belongs to soft skills, and its development becomes more important over time, as this is the type of skills that cannot be automated [3].

Critical thinking means the ability to objectively analyze information and make reasoned judgments. It includes an assessment of data, facts, observed phenomena and research results [4]. According to a survey conducted by [5], business leaders believe that to develop their business they need employees who have the $4 \mathrm{C}$ competencies, that is critical thinking/problem solving, communication, collaboration and creativity. At the same time, most respondents believe that their current employees do not have these skills at the required level. Therefore, management needs to eliminate gaps in these 
skills to compete in the global market in the future.

This applies not only to business, but also to other areas, including education, which gives grounds to focus efforts on developing critical thinking skills in future secondary school teachers in order to teach children these skills and prepare them for future challenges in the labor market. That is why the aim of our study is to development of effective methods of developing critical thinking skills in future teachers during their studies in higher educational institutions.

\section{LITERATURE REVIEW}

The review of the relevant scientific literature shows the growing attention of teachers to the use of various methodologies for the development of students' critical thinking [2].

The authors [6] note that graduates have problems at work due to insufficiently developed skills of critical thinking and problem solving. Conversely, students who think critically and creatively are able to adapt more quickly to the changing world of career development [7].

It is emphasized in the study by [8] that critical thinking is a universal competence that students need, both in future professional activities and in personal life. Therefore, it should be included in university curricula, programs and classes.

[9] emphasized the importance of critical thinking skills and reflective thinking for MBA students. The author argues that these skills allow professionals to make effective decisions, take into account the consequences of their attitudes and actions, as well as make changes in the trajectory of effective work. At the same time, he notes that the MBA is completely detached from the "real world" and has nothing to do with the needs of practicing managers. These effects of critical thinking are fully related to the training of teachers in higher educational institutions, and should be taken into account in the preparation of the content and selecting methods of their teaching.

Different approaches, programs, methods and teaching methods are used by scientists and teachers to develop critical thinking in students. For example, the paper [10] presents one of the learning models - 5E. It promotes the development of critical thinking of students, is based on the use of student experience, helps to increase student activity and involvement in the learning process. The 5E learning model consists of the following five components: interaction, research, explanation, development, and evaluation. Moreover, each of these phases involves the active participation of each student in the learning process.

Also [11] ways to develop critical thinking skills in students, in particular in workshops, are considered. A cycle of reflective critical thinking for environmental education has also been introduced. [12] cites data from his own research project, which consisted of implementing a curriculum of three business courses to increase self-assessment of intentions for success, including such criteria as internal purposefulness, self-efficacy and critical thinking.
[13] implemented a research project to implement a course in forest bioeconomics, built on critical thinking and other skills of the 21 st century (joint design, problem solving, crossborder integration, online and blended learning). The results of the qualitative analysis showed that there are some differences in the experience of students who studied with the use of blended methodology and with the introduction of online courses.

The results of [6] research show that students' critical thinking and collaboration skills can be significantly improved through a multidisciplinary integrated approach relying on project-based learning by combining subjects, competencies and skills to be developed. A study by a group of Indonesian researchers demonstrated the effective impact of problembased learning strategies on the development of students' critical thinking skills in public education.

Another study focused on the effectiveness of the use of smart technologies in the development of critical thinking of law students. According to the authors, the combination of the potential of smart learning technologies and the development of critical thinking in students allows to optimally resolve the contradictions between the needs of modern society and the practice of legal training [14].

The article [8] analyses the methods used to develop critical thinking by teachers from Spain and Latin America. Summarizing the results of the study, the authors conclude that teachers prefer three methods: oral and written thinking and argumentation; reading, analysis and generalization; thematic research, regardless of the concepts of their critical thinking.

[15] studied the development of critical thinking through learning strategies in English classes. The authors propose strategies that include communicative language assignments, the use of authentic meaningful texts, critical literacy, awareness of holistic brain development, acceptance of reflective learning. According to the authors, the integrated use of surveys, collaborative learning, the use of literature in English lessons, creative drama and self-assessment allows students to become autonomous and succeed in learning.

The effectiveness of the method of asynchronous online discussion (AOD) in the development of critical thinking skills was proven in a study by [16]. The author argues that the advantages of the AOD method are the ability for students to learn anytime, anywhere, as well as the time required to process learning material, exchange ideas and points of view. The effectiveness of the method depends on the number of groups participating in the training.

The study by [17] is worth noting, which reveals the content of teaching the effective use of reasoning skills, and, according to the authors, the reasoning of individual students is often biased, while reasoning and discussion in groups give better results. However, the paper provides suggestions for maximizing the thinking capacity of individual students.

Despite the presence in the scientific literature of a number of studies on the development of critical thinking in students, there is still a need to develop new methods that take into 
account the current state and needs of education and modern psychological and pedagogical features of the learning process and test their effectiveness.

\section{METHODS}

The experimental technique involved the development of critical thinking skills in third-year students majoring in 013 "Primary Education". The sample representativeness was ensured by random selection from the general population of 125 people. Given a confidence interval $\mathrm{p}=95 \%$ and a confidence interval of error $\Delta= \pm 0.05$, the sample size was 94 people, divided into the experimental group (EG) of 45 students and a control group (CG) - 49 students. The groups were equalized using a randomization strategy according to the following criteria: age, gender, level of academic performance, the level of critical thinking.
The experiment was conducted according to the scheme "Before-after with the control group". EG students studied a special course "From Reflection to Self-Assessment: Critical Thinking Skills", which was delivered during the first half of the 2019-2020 academic year. The following methods were used in the study: Socratic Dialogue, Basket of Ideas, Osborne's brainstorming, Aquarium, Six Thinking Hats by E. de Bono, Design in Teams, Writing Essays. The control group students were trained without the introduction of this special course.

The level of critical thinking was diagnosed using the Critical Thinking test by [18] adapted by [19: 330-334, 437444]. Table 1 contains benchmark data for the test for students.

Table 1. Benchmark data for the test of critical thinking by Starkey (adapted by Lutsenko)

\begin{tabular}{ccccccc}
\hline Sample & Sample size & \multicolumn{5}{c}{ Level of development } \\
& Very low level & & Law level & Medium level & High level & Very high level \\
\hline Students & 237 & $<7$ & $7-10$ & $11-20$ & $21-25$ & $>25$ \\
Male & 65 & $<7$ & $7-10$ & $11-19$ & $20-23$ & $>23$ \\
Female & 172 & $<6$ & $6-10$ & $11-21$ & $22-26$ & $>26$ \\
\hline
\end{tabular}

We can see from Table 1 that the indicators of the levels of male and female critical thinking differ slightly, but these differences are not significant. Given that the EG and CG were homogeneous in terms of gender, we took the averages given in the line "Students".

The diagnostic procedure consisted of providing each student with texts of questions, each offering four possible answers. According to the instructions in all assignments (except for the first one), it was necessary to choose one of the most correct answers. The subject was awarded one point for each match of the answer with the key. There were 30 minutes for the test, and the assignments for which there were not enough time were considered uncompleted. Students who received less than 7 points on the test were considered to have a very low level of critical thinking. The result of 7-10 points corresponded to a low level, 11-20 points corresponded to a medium average level, 21-25 - to a high level, and more than 25 points - to a very high level.
Academic performance was determined by the ECTS system (European Credit Transfer and Accumulation System (2020): a high level correlated with "A" grade (90-100 points), a sufficient level " $B$ " and " $C$ " grades (75-89 points), a medium level corresponded to " $\mathrm{D}$ " and " $\mathrm{E}$ " grades (60-74 points), the low - to "FX" (36-59) and "F" (1-35 points) grades. The assessment procedure was conducted by the Examination Board consisting of Head of the Primary Education Department and two teachers who taught the specified experimental course.

\section{RESULTS}

To establish a starting point in the situation "before the experiment", we diagnosed critical thinking in EG and CG. Table 2 provides diagnostic results.

Table 2. Levels of critical thinking in students of EG and CG ("before the experiment" situation)

\begin{tabular}{ccccc}
\hline Levels & \multicolumn{2}{c}{ Experimental group } & \multicolumn{2}{c}{ Control group } \\
& People & $\%$ & People & $\%$ \\
Very high & 0 & 0 & 0 & 0 \\
High & 8 & 18.0 & 10 & 21.0 \\
Medium & 27 & 60.0 & 31 & 63.0 \\
Low & 10 & 22.0 & 8 & 26.0 \\
Very low & 0 & 0 & 0 & 0 \\
\hline
\end{tabular}




\section{Total:}

45

100

49

100

Statistical analysis of data in Table 1 showed that there were no students with very high and very low levels of critical thinking in both EG and CG. The rest of the data in Table 2 were distributed as follows: a high level of the studied trait was recorded in $18 \%$ of students in the experimental group and in $21.0 \%$ of the control group; medium level - in $60.0 \%$ and $63 \%$; low - in $22.0 \%$ and $26 \%$, respectively. The calculation of Pearson's chi-squared test indicates almost the same distribution of respondents' shares according to the levels of critical thinking (empirical value $\chi 2=0.551$, critical value $\chi 2$ at the significance level $\mathrm{p}<.05$ is 5.991).

We also compared the performance of students of EG and CG in the situation "before the experiment" (Table 3).

Table 3. Levels of academic performance of EG and CG students ("before the experiment" situation)

\begin{tabular}{ccccc}
\hline Levels of academic performance & \multicolumn{2}{c}{ Experimental group } & \multicolumn{2}{c}{ Control group } \\
\hline & People & $\%$ & People & $\%$ \\
High & 3 & 7.0 & 4 & 8.0 \\
Sufficient & 14 & 31.0 & 14 & 29.0 \\
Medium & 22 & 49.0 & 25 & 51.0 \\
Low & 6 & 13.0 & 6 & 12.0 \\
Total: & 45 & 100 & 49 & 100 \\
\hline
\end{tabular}

The data of Table 3 show that the distribution of student shares by levels of academic performance is identical: a high level was recorded in $7 \%$ of EG and $8 \%$ of CG. Similarly, a sufficient level was recorded in $31 \%$ and $29 \%$, medium - in $49 \%$ and $51 \%$, low - in $13 \%$ and $12 \%$. In summary, we can say that the discrepancy between the particles is one to two percent. This trend is confirmed by statistical calculations: the empirical value of $\chi^{2}$ is 0.164 , while the critical value of $\chi^{2}$ at a significance level of $\mathrm{p}<.05$ is 7.815 . Thus, the above calculations confirm the lack of significant differences between $\mathrm{EG}$ and $\mathrm{CG}$ in the levels of student academic performance.

Teaching of the special practical course ended with the final testing of EG and CG students using the Critical Thinking test of [18] adapted by [19] (Table 4).

Table 4. Levels of critical thinking in students of EG and CG ("post-experiment" situation)

\begin{tabular}{ccccc}
\hline Levels & \multicolumn{2}{c}{ Experimental group } & \multicolumn{2}{c}{ Control group } \\
& People & $\%$ & People & $\%$ \\
\hline Very high & 3 & 7.0 & 0 & 0 \\
High & 17 & 38.0 & 11 & 23.0 \\
Medium & 25 & 55.0 & 32 & 65.0 \\
Low & 0 & 0 & 6 & 12.0 \\
Very low & 0 & 0 & 0 & 0 \\
Total: & 45 & 100 & 49 & 100 \\
\hline
\end{tabular}

Analysis of table 4 showed significant differences between EG and CG (the empirical value of $\chi^{2}$ is 10.995, which exceeds the critical value $\chi 2=7.815$ at a significance level of $\mathrm{p}=0.05)$. First of all, it should be noted that in EG 3 students (7\%) developed critical thinking to a very high level, while CG students didn't demonstrate this. The share of students with a high level has considerably increased in EG in comparison

Table 5. Changes in the levels of critical thinking in EG students (comparison of situations "before the experiment" and "postexperiment") with CG: $38 \%$ as opposed to $23 \%$, that is the difference makes $15 \%$. In addition, $6 \mathrm{EG}$ students (13\%) increased their level from low to medium, while this figure remained unchanged in CG.

For a more detailed analysis, we will compare the changes in the EG before and after the experiment (Table 5). 


\begin{tabular}{ccccc}
\hline \multirow{2}{*}{ Levels } & \multicolumn{2}{c}{ After the experiment } & \multicolumn{2}{c}{ Before the experiment } \\
& People & $\%$ & People & $\%$ \\
\hline Very high & 3 & 7.0 & 0 & 0 \\
High & 17 & 38.0 & 8 & 18.0 \\
Medium & 25 & 55.0 & 27 & 60.0 \\
Low & 0 & 0 & 10 & 22.0 \\
Very low & 0 & 0 & 0 & 0 \\
Total: & 45 & 100 & 45 & 100 \\
\hline
\end{tabular}

Analyzing Table 5, we can see that the number of EG students with a high level more than doubled (17 vs. 8), and three students reached a very high level of critical thinking as a result of the conducted experimental work. Instead, 10 students who had a low level raised it to a medium level. The statistical significance of these changes is confirmed by the value of $\chi 2$ (16.317), which exceeds the critical value (11.345) at a significance level of $p<0.01$. Fig. 1 shows the described changes.

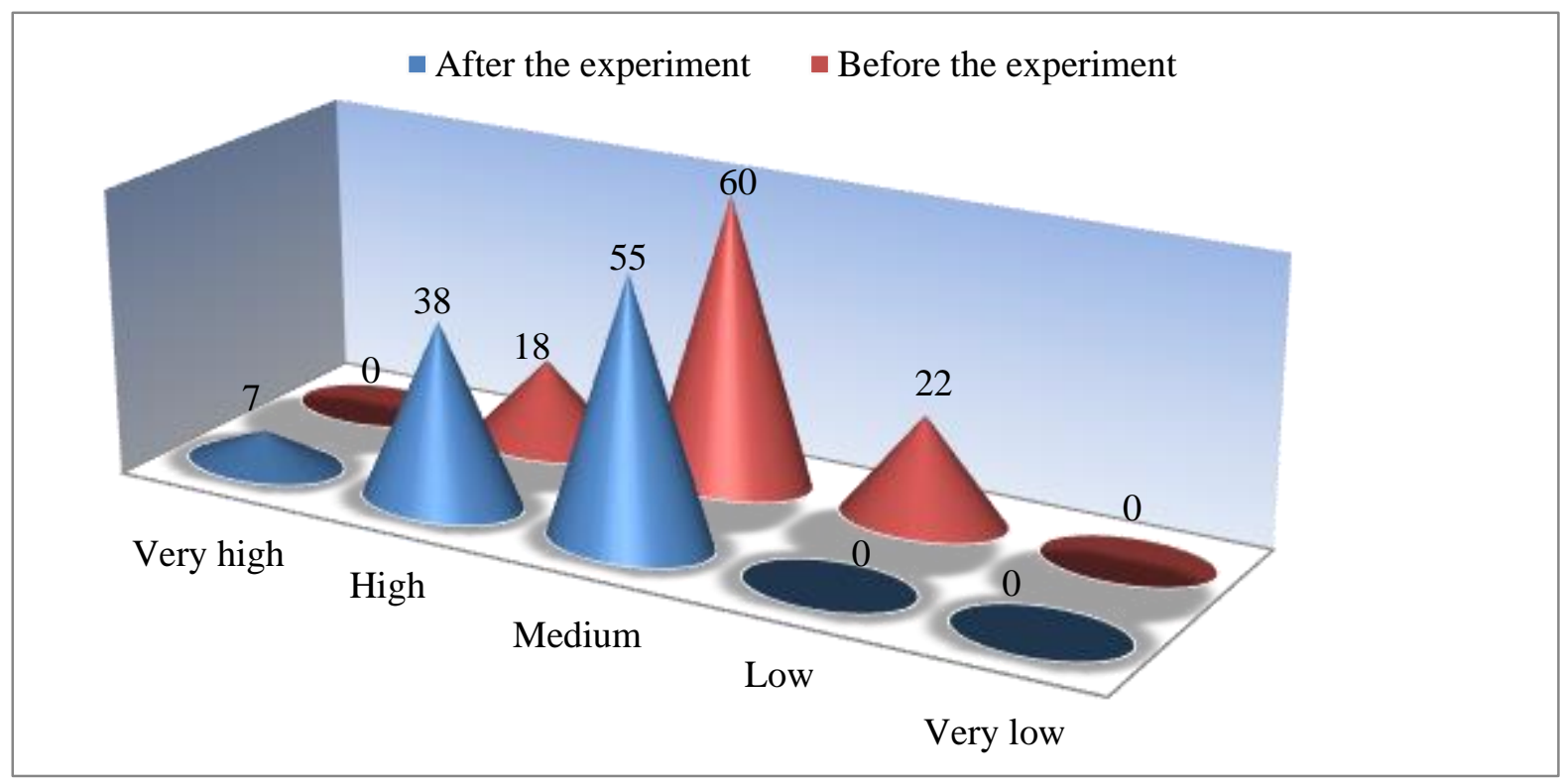

Fig. 1.Changes in the level of critical thinking in EG students as a result of the experiment (in \%)

The obtained results were also characterized by qualitative features. Thus, three students $(7 \%)$ achieved a very high level of test performance. This meant that they had developed skills of critical thinking, such as logic, induction, deduction, reflection. They can control their emotions well, analyse information for authenticity, have the ability to recognize their illusions, manipulation by others, advertising, propaganda.

In addition, they are able to separate estimates and assumptions from the facts, identify causal relationships or accept their absence, recognize the limitations of their mental processes, make the most optimal decisions in conditions of uncertainty and risk. Therefore, they are able to set realistic goals and find adequate ways to achieve them. Such competencies enable them to be an effective professional in all types of work, which requires complex and responsible decisions, as well as give a general advantage in life and adaptation to changing conditions of the environment.
There were 17 students (38\%) who received a high level for the test. These students have the majority (80-90\%) of critical thinking skills - logic, induction and deduction, control over emotions, are critical of persuasion and manipulation techniques, are able to set goals and build a strategy to achieve them. However, some critical thinking skills may not be available at this level. For example, these include the most complex processes of information analysis and thinking screening or re-examining pseudo-reliable sources of information, resistance to distraction techniques, distrust of evaluative judgments instead of facts, identifying real problems rather than "catchy" (which may not actually require a solution), deep reflection. According to the author of the test, such a person can achieve a higher level of critical thinking, if he develops it in accordance with the proposed training and programs for the development of critical thinking. The medium test results were obtained by 25 EG students (55\%). 
Each student at this level has a significant number (30-70\%) of critical thinking skills - logic, including advanced induction and deduction procedures, the ability to critically analyse information, a certain ability to resist manipulation (being probably not immediately aware of them), control over emotions and understanding of their influence on decisionmaking. At the same time, these abilities are underdeveloped because such students did not correctly recognize 30 to $70 \%$ of persuasion techniques: distraction, erroneous conclusions, did not choose optimal solutions and trusted unreliable sources of information that were simulated in the test. The author of the test claims that the number of optimal decisions in such individuals may be approximately equal to the number of unsuccessful ones, but based on knowledge of successful decisions, they may not realize the lack of efficiency and limitations of their thinking. Therefore, at this level of critical thinking, the student must allocate time and energy for its development, as this can be a serious growth potential for him. There were low test scores in 10 (22\%) EG students before the experiment. This showed that these students did not have enough critical thinking skills (less than 30\%), which often leads to mistakes, unsuccessful decisions, accumulation of problems in learning and life in general. Such people can often be a victim of manipulation, propaganda, unfair advertising; they can fall victim to scammers and manipulators without even realizing it. They may perceive clever manipulators as their true friends or benefactors, while honest and reliable people - as enemies or foes. People with a low level of blurred critical thinking cannot effectively build arguments, and therefore will often encounter misunderstandings in discussions, which turns into useless and unconstructive arguments, may feel offended, underestimated, will tend to mystical and fatal explanation of the world, because objective and logical explanation is not available enough to them. Such people can often be disappointed in different people, ideas, processes, because they tend to entertain illusions that do not correspond to reality, develop ineffective behavioral strategies. In this case, the author of the test strongly recommends the development of critical thinking skills in all available ways.
A very low level of the test indicates that this individual copes with only $10-20 \%$ of assignment that require the use of critical thinking. Although there was no student among those who participated in the experiment who received very low scores for the test, they were introduced to different levels (including very low) of critical thinking while studying the proposed special course. Thus, subjects with a very low level of critical thinking have poorly developed logic, induction and deduction processes, the ability to filter out inaccurate information and collect objective one, detect manipulations, illusions and misconceptions, make informed decisions, argue, realize own biases. People with this level feel incomprehensible or incompetent in intellectual disputes. They will try to cheat, dodge or resort to aggression, as they are not able to provide clear and convincing arguments. These subjects are characterized by various substitutions of thinking by beliefs.

Such people often get to totalitarian sects or become supporters of right-wing radical and authoritarian ideologies, they may distrust science and oppose the dissemination of knowledge, they may have alcohol, gaming, television and other addictions. They obey ancient instincts and make little use of the adaptive capabilities of the mind. In addition, they often do not realize their own mistakes, they become "pawns" in someone else's game [19: 330-334].

Changes in the learning performance of EG and CG students were also studied in the "post-experiment" situation. For this purpose, Table 6 presents the generalized results of academic performance for the semester.

Comparison of indicators of academic performance provided in Table 6 showed that the share of EG students with high and sufficient levels of success is $65 \%$, while this figure is $41 \%$ in CG. The differences between EG and CG are confirmed by statistical calculations: the calculated value of $\chi 2$ is 8.188 with a critical value of this criterion 7.815 at a significance level of $p<0.05$. Fig. 2 presents analysed data.

Table 6. Levels of academic performance of EG and CG students ("post- experiment" situation)

\begin{tabular}{|c|c|c|c|c|}
\hline \multirow{2}{*}{ Levels of academic performance } & \multicolumn{2}{|c|}{ EG } & \multicolumn{2}{|c|}{ CG } \\
\hline & People & $\%$ & People & $\%$ \\
\hline High & 9 & 21.0 & 4 & 8.0 \\
\hline Sufficient & 20 & 44.0 & 16 & 33.0 \\
\hline Medium & 16 & 35.0 & 25 & 51.0 \\
\hline Low & 0 & 0 & 4 & 8.0 \\
\hline Total: & 45 & 100 & 49 & 100 \\
\hline
\end{tabular}




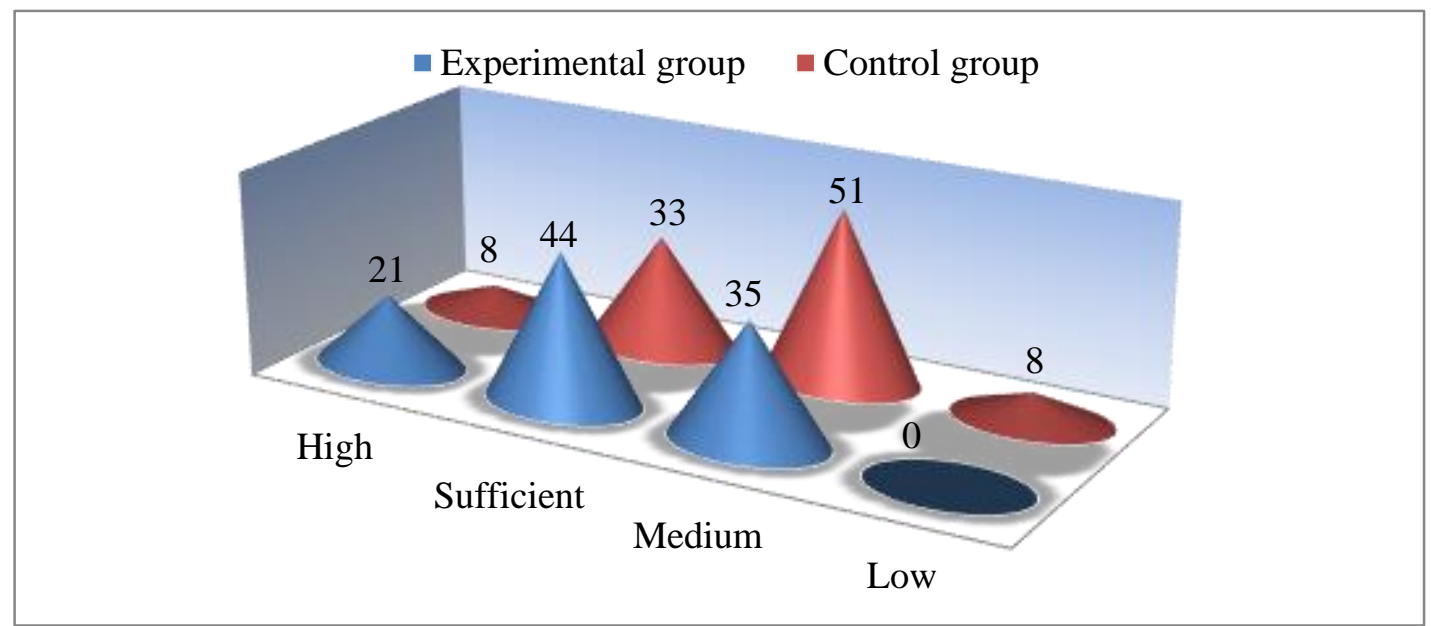

Fig. 2. Comparison of the academic performance of EG and CG students in the "post- experiment" situation (in \%)

The above gives reason to believe that as a result of the experiment, the academic performance of EG students has significantly improved in comparison with CG. However, the question arises as to how significant were the changes in EG after the experiment compared to the situation before the experiment. The relevant data were entered in Table 7 to clarify this.

Table 7. Changes in the academic performance of EG students

\begin{tabular}{ccccc}
\hline \multirow{2}{*}{ Levels of academic performance } & \multicolumn{2}{c}{ After the experiment } & \multicolumn{2}{c}{ Before the experiment } \\
& People & $\%$ & People & $\%$ \\
\hline High & 9 & 21.0 & 3 & 7.0 \\
Sufficient & 20 & 44.0 & 14 & 31.0 \\
Medium & 16 & 35.0 & 22 & 49.0 \\
Low & 0 & 0 & 6 & 13.0 \\
Total: & 45 & 100 & 45 & 100 \\
\hline
\end{tabular}

Analysis of Table 7 shows that the academic performance rates in EG significantly improved after the experiment. In particular, the number of students with high level doubled to 6 as opposed to 3 before the experiment. Instead, the number of intermediate and low-level students decreased to 16 and 3 , respectively, compared to 22 and 6 in the "pre-experiment" situation. The analyzed changes are confirmed by statistical calculations: the empirical value of $\chi^{2}$ is 11.006 , while the critical value of $\chi^{2}$ is 7.815 at a significance level of $p=0.05$. Fig. 3 is a graphical representation of this trend.

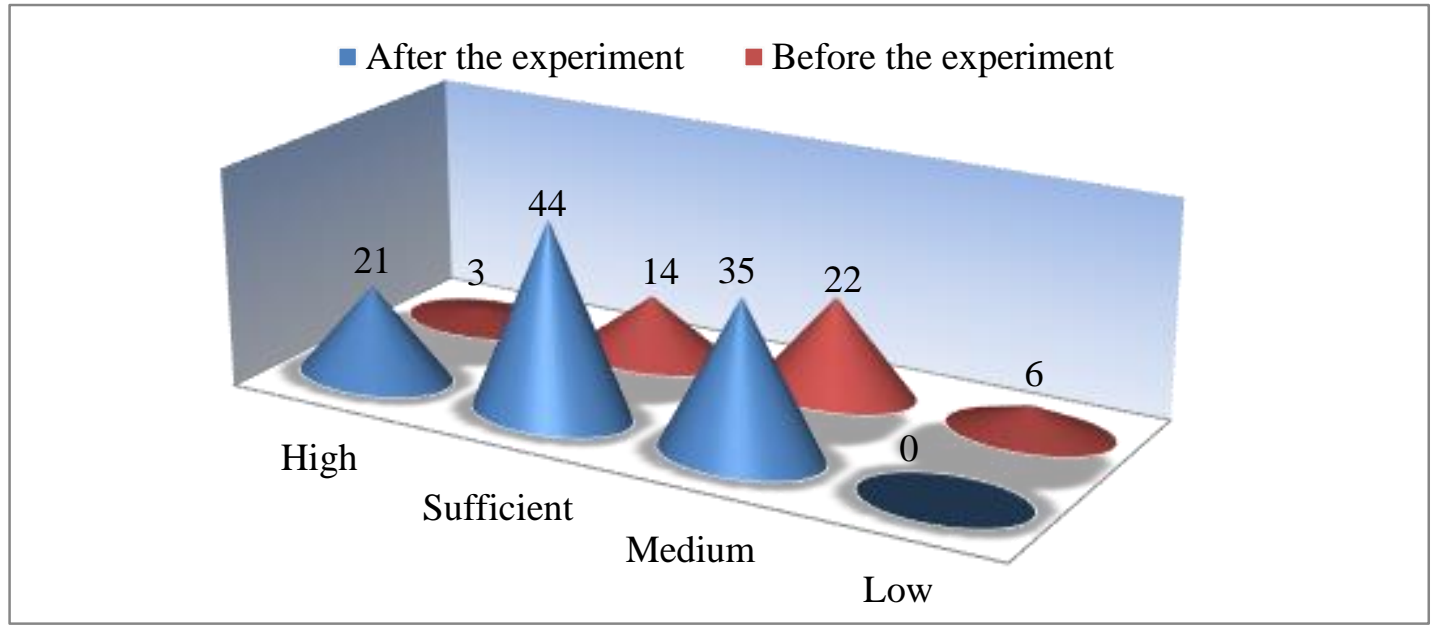

Fig. 3. Changes in the academic performance of EG students as a result of the experiment (in \%) 
One of the objectives of our study was to establish the impact of the development of critical thinking on student academic performance. Table 8 was prepared in order to test this hypothesis, which contains generalized data of EG students on the levels of critical thinking (factor trait) and academic performance (resulting trait).

Table 8. The impact of the development of critical thinking on the academic performance of EG students

\begin{tabular}{|c|c|c|c|c|c|}
\hline \multirow[b]{2}{*}{ Levels of critical thinking } & \multicolumn{4}{|c|}{ Levels of academic performance } & \multirow{2}{*}{ Total } \\
\hline & High & Sufficient & Medium & Low & \\
\hline Very high & 3 & 0 & 0 & 0 & 3 \\
\hline High & 6 & 11 & 0 & 0 & 17 \\
\hline Medium & 0 & 9 & 16 & 0 & 25 \\
\hline Low & 0 & 0 & 0 & 0 & 0 \\
\hline Very low & 0 & 0 & 0 & 0 & 0 \\
\hline Total & 9 & 20 & 16 & 0 & 45 \\
\hline
\end{tabular}

As the results of diagnostics in the group did not record low and very low levels of critical thinking, as well as low levels of academic performance, cells with zero values were not taken into account to calculate the statistical criterion $\chi 2$ and the Chuprov's correlation. Therefore, the calculated Chuprov's coefficient is equal to $\mathrm{C}=0.458$, and is statistically significant at the confidence level $\mathrm{p}<.01$ (the value of the calculated $\chi 2$ is 32,693 , the critical value of $\chi 2$ at the significance level $p=0.01$ is 13.277 , so the correlation between factor and resulting traits is statistically significant at a significance level of $\mathrm{p}<0.01$ ). Thus, the influence of the development of critical thinking on improving academic performance can be considered proven.

\section{DISCUSSION}

We the results in this paper obtained during the experimental study were achieved through the consistent development of a wide range of skills that are part of critical thinking in students. Methods such as the Socratic Dialogue, the Basket of Ideas, the Brainstorming by A. Osborne, the Aquarium, and The Six Hats of Thinking by E. de Bono, Designing in Teams, and Essay Writing were used. The most important component of critical thinking is reflexive thinking, as it enables students to conceptualize critical reflection as a process that enhances self-awareness, promotes the application of theory in practice, and reinforces aspects of their professional identity $[10,20]$. In addition, reflexive thinking is an effective cognitive tool for understanding their own strengths and weaknesses, in choosing strategies for solving problems.

[21] proved the influence of self-reflection on the development of critical thinking was proved in their study: respondents who believed they had more introspection and understanding reported more critical thinking in their professional activities. Metacognitive awareness, which means the ability of an individual to realize and regulate the process of self-knowledge, is close to the concept of self-reflection. The study by [22] found that when students are able to control their cognitive processes, they approach the facts given to them more critically and more judiciously evaluate the information they receive from the environment. The authors found that the development of metacognitive awareness skills leads to an increase in the level of critical thinking.
Much attention in the method of development of critical thinking offered in this work was paid to the development of metacognition skills through careful selection of questions using different cognitive models, in particular, Socratic dialogue, Paul \& Elder taxonomy, which helped students learn to think correctly and ask questions. In particular, [23] emphasizes this aspect of the problem in his study.

[24] confirms the effectiveness of this combination of methods in his study: he evaluated the correlation between higher-order thinking skills (reflexive thinking, critical thinking) and self-control, which contribute to the academic performance of university students. The results of the study showed that critical thinking and all components of reflective thinking have a positive and reliable impact on academic performance, with reflection and self-control having the greatest impact.

Significant progress in teaching critical thinking has been achieved through a combination of self-assessment and reflection of students during the pre-test, as well as during the completion of special exercises to develop competencies such as the ability to clearly formulate problems, find, analyse and interpret relevant information, draw correct conclusions and make explanations [25].

[26] noted in their study that an important way to solve the problems of sustainable development is the formation of critical thinking skills in students-future teachers. The study found a positive impact of the use of case studies on the development of their critical thinking skills.

The developed model 5E [10], according to Cohen's classifier, has a very high efficiency in the development of critical thinking and improving student performance, compared to traditional teaching methods. As our research has shown, the method of developing critical thinking developed in this paper also has a positive effect on academic performance, in particular, the number of students with a high level of success has doubled, and with a low level - decreased. In addition, thanks to our methodology, the level of critical thinking of students has more than doubled.

The method developed by us provides application of a method of team work that, besides development of skills of critical thinking, positively influences to interact and cooperate, which is also confirmed by research of [27]. 
We found in our study that those students who had a higher level of desire for truth-seeking and self-development had the best results in the development of critical thinking. This raises the question of the need for separate studies of the impact of such dispositions as curiosity, openness, systematicity, truthseeking, self-confidence, maturity on critical thinking.

Another aspect that needs further research is the introduction of the development of critical thinking in the higher education system of Ukraine, as it is essential for the socio-economic development of the country. For example [28] draws attention to this in his study of the state of teaching critical thinking in educational institutions in Indonesia.

\section{CONCLUSION}

The results of the study showed the effectiveness of developing critical thinking in students in teaching a special practical course according to the methodology developed in this study. The EG (45 people) was formed using the method of random selection, where students studied a special practical course delivered during the first half of the 2019-2020 academic year. This course was not delivered in the CG (49 people). The level of critical thinking was diagnosed using the Starkey's Critical Thinking test adapted by Lutsenko [18, 19].

Interpretation of the test results allowed dividing EG students into very high, high, medium, low and very low levels of critical thinking, as well as providing qualitative characteristics. According to the results of the experiment in EG, the number of students with a high level has more than doubled. Besides, we proved that the development of critical thinking has a positive effect on academic performance: the number of students with a high level doubled, and the number of students with a low level decreased.

The obtained results were achieved due to used teaching methods "Socratic dialogue", "Basket of ideas", "Brainstorming" by A. Osborne, "Aquarium", "Six hats of thinking" by E. de Bono, "Designing in teams", "Writing essays", which contributed reflexive thinking, self-analysis, awareness of one's achievements and shortcomings, ability to choose a strategy for solving problems. This was also facilitated by metacognitive awareness skills: students learned to critically and thoughtfully analyse and evaluate information and make informed decisions; correctly use cognitive models of learning (Socratic dialogue, Paul \& Elder taxonomy, which helped them to think correctly and ask questions). The success of proposed in this paper methods of developing critical thinking in students was achieved through a comprehensive combination of self-assessment and reflection, performing exercises to develop the ability to clearly articulate the problem, find, analyse and interpret relevant information, draw the right conclusions and explanations. This makes it a highly effective tool for developing students' critical thinking. Further research is needed on the role of dispositional self-regulation of an individual in the development of critical thinking skills, as well as the impact of critical thinking on the professional success of graduates of pedagogical specialties.

\section{CONFLICT OF INTERESTS}

The authors declare that there is no conflict of interest.

\section{References}

[1] World Economic Forum. (Oct. 2020). The Future of Jobs. Report 2020. [Online] Available: http://www3.weforum.org/docs/WEF_Future_of_Jobs_20 20.pdf

[2] R. M. Schmaltz, E. Jansen and N. Wenckowski, (2017). "Redefining critical thinking: Teaching student to think like scientists," Front Psychol, vol. 8, no. 459. [Online] Available: https://doi.org/10.3389/fpsyg.2017.00459

[3] E. Charlton (Jan. 14, 2019). These Are the 10 Most InDemand Skills of 2019, According to LinkedIn. [Online] Available: https://www.weforum.org/agenda/2019/01/thehard-and-soft-skills-to-futureproof-your-career-accordingto-linkedin/

[4] A. Doyle, (June 8, 2020). Critical Thinking Definition, Skills, and Examples. [Online] Available: https://www.thoughtco.com/critical-thinking-definitionwith-examples-2063745

[5] American Management Association. (Jan. 24, 2019). AMA Critical Skills Survey: Workers Need Higher Level Skills To Succeed in the 21st Century. [Online] Available: https://www.amanet.org/articles/ama-critical-skills-surveyworkers-need-higher-level-skills-to-succeed-in-the-21stcentury/

[6] H. Trisdiono, "Multidisciplinary integrated project-based learning to improve critical thinking skills and collaboration." Int J LearnTeach Educ Res, vol. 18, no. 1, pp. 16-30, 2019.

[7] N. W. Suarniati, I. W. Ardhana, N. Hidayah and D. M. Handarini, "The difference between the effects of problem-based learning strategy and conventional strategy on vocational school students' critical thinking skills in civic education," Int J Learn Teach Educ Res, vol. 18, no. 8, pp. 155-167, 2019.

[8] M. José, B. D. Fernández-Nogueira, M. Poblete and H. Galindo-Domínguez, (2019). "Methodologies for teaching-learning critical thinking in higher education: The teacher's view," Think Skills Creativ, vol. 33 [Online] Available: https://doi.org/10.1016/j.tsc.2019.100584

[9] S. E. Norris, (2018). Research Anthology on Developing Critical Thinking Skills in Students. [Online] Available: https://www.semanticscholar.org/paper/TheDevelopment-of-the-Entrepreneurial-Mindset\%2C-andNorris/50a11a6ed7519998c75923a2c76106fa90e7a4c2

[10] Y. Sulaiman, M. A. Rahman and N. Kamariah Nik Mat, "Enhancing Student Active Learning in Consumer Behaviour Class using 5E Learning Cycle: A Conceptual Paper," WSEAS Transactions on Environment and Development, vol. 16, pp. 520-529, 2020.

[11] E. Reyes-Chua, N. R. Navigar, M. J. M. Campaa, R. A. Ymana, R. J. M. Ventayen and I. C. A. Ymana, "Reflective Critical Thinking Skills of Student Leaders in Higher Education Institutions for Development," WSEAS Transactions on Environment and Development, vol. 17, 
pp. 418-428, 2021.

[12] H. Nold, "Using critical thinking teaching methods to increase student success: An action research project," International Journal of Teaching and Learning in Higher Education, vol. 29, no. 1, pp. 17-32, 2017.

[13]H. Vuojärvi, M. Eriksson and H. Vartiainen, "Crossboundary collaboration and problem-solving to promote 21 st century skills - Students' experiences international," Int J Learn Teach Educ Res, vol. 18, no. 13, pp. 30-60, 2019.

[14] I. Kopotun, M. Yu. Durdynets, N. V. Teremtsova, L. L. Markina and L. M. Prisnyakova, "The use of smart technologies in the professional training of students of the law departments for the development of their critical thinking," Int J Learn Teach Educ Res, vol. 19, no. 3, pp. 174-187, 2020.

[15] Ş. Orakcı, M. Durnali and O. Aktan, Fostering Critical Thinking Using Instructional Strategies in English Classes, Hershey: IGI Global, 2021.

[16]M. K. Afify, "The influence of group size in the asynchronous online discussions on the development of critical thinking skills, and on improving students' performance in online discussion forum," Int J Emerg Technol Learn, vol. 14, no. 5, pp. 132-152, 2019.

[17]H. Mercier, M. Boudry, F. Paglieri and E. Trouche, "Natural-born arguers: Teaching how to make the best of our reasoning abilities," Educ Psychol, vol. 52, no. 1, pp. 1-16, 2017.

[18]L. Starkey, Critical Thinking Skills Success in 20 Minutes a Day, 2nd edition, New York: Learning Express, 2010.

[19] O. L. Lutsenko, "Regularities of psychological adaptation of man at the present stage of evolution," Doctoral dissertation, V. N. Karazin Kharkiv Nat Univ, Kharkiv, 2018.

[20] L. Whitaker and E. Reimer, "Students' conceptualisations of critical reflection," Soc Work Educ, vol. 36, no. 8, pp. 946-958, 2017.

[21]C. Fen-Fang, C. Shu-Yueh and P. Hsiang-Chu, "Selfreflection and critical thinking: The influence of professional qualifications on registered nurses," Contemp Nurse, vol. 55, pp. 1-22, 2019.

[22] M. Celebi and B. N. Kusucuran, "Öğrencilerin bilişötesi farkındalık ve eleştirel düşünme düzeylerinin incelenmesi," Int J Innov Res Educ, vol. 5, no. 4, pp. 129144, 20108.

[23] J. S. Nappi, "The importance of questioning in developing critical thinking skills," Delta Kappa Gamma Bull Int J Prof Educ, vol. 84, no. 1, pp. 30-41, 2017.

[24]A. Ghanizadeh, "The interplay between reflective thinking, critical thinking, self-monitoring, and academic achievement in higher education," Higher Educ, vol. 74, pp. 101-114, 2017.

[25] World Economic Forum. (Jan. 2016). The Future of Jobs Employment, Skills and Workforce Strategy for the Fourth industrial Revolution. 2016. Global Challenge Insight Report. [Online] Available: http://www3.weforum.org/docs/WEF_Future_of_Jobs.pdf

[26]Z. Strakova and I. Cimermanova, "Critical thinking development - A necessary step in higher education transformation towards sustainability, Sustainability, vol. 10, no. 10, Art. 3366, 2018.

[27] N. F. Plotnikova and E. N. Strukov, "Integration of teamwork and critical thinking skills in the process of teaching students," Cypr J Educ Sci, vol. 14, no. 1, pp. 001-010, 2019.

[28] I. Hamzah, "Historical perspective: The development of critical thinking in Indonesian ELT", J ELT Res, vol. 2, pp. 89-102, 2017.

\section{Contribution of individual authors to the creation of a scientific article (ghostwriting policy)}

All authors contributed equally to the creation of the given scientific article.

\section{Creative Commons Attribution License 4.0 (Attribution 4.0 International , CC BY 4.0)}

This article is published under the terms of the Creative Commons Attribution License 4.0

https://creativecommons.org/licenses/by/4.0/deed.en_US 